\title{
Comparative phosphoproteome analysis to identify candidate phosphoproteins involved in blue light-induced brown film formation in Lentinula edodes
}

\author{
Tingting Song ${ }^{1}$, Yingyue Shen ${ }^{1}$, Qunli Jin ${ }^{1}$, Weilin Feng ${ }^{1}$, Lijun Fan ${ }^{1}$, Weiming Cai ${ }^{\text {Corresp. } 1}$ \\ ${ }^{1}$ Institute of Horticulture, Zhejiang Academy of Agricultural Sciences, Hangzhou, China \\ Corresponding Author: Weiming Cai \\ Email address: caiwm0527@126.com
}

Light plays an important role in the growth and differentiation of Lentinula edodes mycelia, and mycelial morphology is influenced by light wavelengths. The blue light-induced formation of brown film on the vegetative mycelial tissues of $L$. edodes is an important process. However, the mechanisms of $L$. edodes' brown film formation, as induced by blue light, are still unclear. Using a high-resolution liquid chromatography-tandem mass spectrometry integrated with a highly sensitive immune-affinity antibody method, phosphoproteomes of $L$. edodes mycelia under red- and blue-light conditions were analyzed. A total of 11,224 phosphorylation sites were identified on 2,786 proteins, of which 9,243 sites on 2,579 proteins contained quantitative information. In total, 475 sites were up-regulated and 349 sites were down-regulated in the blue vs red group. To characterize the differentially phosphorylated proteins, systematic bioinformatics analyses, including gene ontology annotations, domain annotations, subcellular localizations, and Kyoto Encyclopedia of Genes and Genomes pathway annotations, were performed. These differentially phosphorylated proteins were correlated with light signal transduction, cell wall degradation, and melanogenesis, suggesting that these processes are involved in the formation of the brown film. Our study provides new insights into the molecular mechanisms of the blue light-induced brown film formation at the post-translational modification level. 
2 Comparative phosphoproteome analysis to identify

3 candidate phosphoproteins involved in blue light-

4 induced brown film formation in Lentinula edodes

7 Tingting Song ${ }^{1}$, Yingyue Shen ${ }^{1}$, Qunli Jin ${ }^{1}$, Weilin Feng ${ }^{1}$, Lijun Fan ${ }^{1}$, Weiming Cai ${ }^{1 *}$

8

9 Institute of Horticulture, Zhejiang Academy of Agricultural Sciences, Hangzhou, Zhejiang, 10 China

12 Corresponding author:

13 Weiming Cai

14198 Shiqiao road, Hangzhou, Zhejiang, 310021,China

15 E-mail: CaiWM527@126.com; 


\section{Abstract:}

35 Light plays an important role in the growth and differentiation of Lentinula edodes mycelia, and mycelial morphology is influenced by light wavelengths. The blue light-induced formation of brown film on the vegetative mycelial tissues of $L$. edodes is an important process. However, the mechanisms of L. edodes' brown film formation, as induced by blue light, are still unclear. Using a high-resolution liquid chromatography-tandem mass spectrometry integrated with a highly sensitive immune-affinity antibody method, phosphoproteomes of L. edodes mycelia under redand blue-light conditions were analyzed. A total of 11,224 phosphorylation sites were identified on 2,786 proteins, of which 9,243 sites on 2,579 proteins contained quantitative information. In

43 total, 475 sites were up-regulated and 349 sites were down-regulated in the blue vs red group. To 44 characterize the differentially phosphorylated proteins, systematic bioinformatics analyses, 45 including gene ontology annotations, domain annotations, subcellular localizations, and Kyoto 46 Encyclopedia of Genes and Genomes pathway annotations, were performed. These differentially 47 phosphorylated proteins were correlated with light signal transduction, cell wall degradation, and 48 melanogenesis, suggesting that these processes are involved in the formation of the brown film. 49 Our study provides new insights into the molecular mechanisms of the blue light-induced brown film formation at the post-translational modification level. 
52 Keywords: brown film formation; Lentinula edodes; light sensing; mycelia; phosphorylation;

53 post-translational modification

\section{INTRODUCTION}

72 Lentinula edodes, also known as shiitake mushroom, belonging to Lentinus, is a valuable

73 medicinal and edible fungus (Ozcelik \& Peksen 2007). It is a popular edible mushroom and the

74 third most cultivated mushroom in the world(Philippoussis et al. 2000). During cultivation, there 
75 are at least four growth stages: vegetative mycelial growth with growth substrate colonization,

76 the light-induced brown film formation, primordial formation, and fruiting body

77 development(Aleksandrova et al. 1998). The brown film formation on the surface of mature

78 mycelia usually appears on the fruiting body primordia and may represent a speciation

79

80 step(Aleksandrova et al. 1998; Chum et al. 2008; Tsivileva et al. 2005). In addition, the mycelial surface does not form a brown film, which is easily occupied by pathogenic organisms, such as bacteria, green molds and fungi(Koo et al.). Light signals are essential factors in the formation of brown films(Tang et al. 2013; Yin et al. 2017; Zhang et al. 2015). The basic genetic regulatory mechanisms of brown film formation and the influence of environmental factors, especially light, remain unclear. Comparative transcriptome studies revealed that the mechanisms of lightinduced brown film formation are related to photosensitivity, signal transduction pathways, and melanin deposition(Tang et al. 2013). Several gene ontology (GO) classifications related to brown film formation were revealed by two-dimensional electrophoresis combined with the matrix-assisted laser desorption/ionization tandem time-of-flight mass spectrometry approach and included small molecule metabolic processes, response to oxidative stress, and organic substance catabolic processes(Tang et al. 2016). Jim et al. compared the morphological changes and gene expression of Lentinus edodes under blue light and continuous dark conditions. Their results indicated that the differential genes were involved in the morphological development of primordia and embryonic muscle, cell adhesion and the structure of cellulose and non-cellulose cell walls that affect the development of fruiting bodies, as well as photoreceptors of blue light signals for fruiting body development and pigment formation (Kim et al,2020). Blue light is an important environmental factor in inducing primordial differentiation and the fruiting body development of mushrooms, such as Hypsizygus marmoreus, Pleurotus ostreatus, and Coprinus cinereus(Kues et al. 1998; Terashima et al. 2005; Xie et al. 2018).

During the growth and development of fungi, the influence of light is very important, and it is also necessary for their growth and development(Crosson et al. 2003). As an external signal, light regulates mycelial growth, primordial differentiation, fruiting body formation, gene expression, and metabolite and enzyme activities through complex light-sensing systems(Cohen et al. 2013; Miyake et al. 2005; Wu et al. 2013; Zhang et al. 2013). At least 100 kinds of fungi have light-perception systems, including red, blue, green, and near-violet(Casas-Flores et al. 2006). Photoreceptors are proteins that harvest light and produce signals that are then transported to the nucleus to activate the transcription of light-responsive genes(Hurley et al. 2012). The white collar-1/white collar-2 (WC-1/WC-2) complex is the main blue-light sensor in Neurospora 
108 crassa, a model organism for studying photoperiod(Dunlap 2006; Linden \& H.). Other blue-light

109 receptors have been successfully identified and cloned, such as the dst 1 and dst2 genes in $C$.

110 cinereus, phrA and phrB in L. edodes, Cmwc-1 in different strains of Cordyceps militaris, and

111 Slwc-1 from Sparassis latifolia(Kuratani et al. 2010; Sano et al. 2009; Sano et al. 2007;

112 Terashima et al. 2005; Yang et al. ; Yang et al. 2012). However, the molecular mechanisms of

113 blue light-induced brown film formation are still unknown.

114 With the determinations and in-depth analyses of genome and transcriptome sequences of

115 model organisms, such as Arabidopsis thaliana, researchers have realized that it is impossible to

116 understand the functions of organisms from only a gene-based perspective(Abbott 2001).

117 Proteomics studies the compositions, expressions, structures, functions, interactions between

118 proteins and their activities(Graves \& Haystead 2002). Isobaric tags for relative and absolute

119 quantification/tandem mass tag (iTRAQ/TMT)-labeling combined with tandem mass

120 spectrometry is a high-throughput quantitative proteomics application technology developed in

121 recent years(Zhan et al. 2019). Compared with relatively stable genomes, proteins are diverse

122 and changeable. In addition, the presence of post-translational modifications (PTMs) and protein

123 processing, such as phosphorylation, glycosylation, and acetylation, are not comparable at the

124 genome or RNA level(Piehler 2005). Proteomics research is a cutting-edge technique in the

125 edible fungi industry. With the effects of abiotic stresses on protein expression levels have been

126 studied the most(Hernandez-Macedo et al. 2002; Liang et al. 2007).

127 In this study, an immunoaffinity analysis combined with high-resolution liquid

128 chromatography-tandem mass spectrometry (LC-MS/MS) was used to study the global

129 phosphorylated proteome of brown films induced by blue light. This study provides new insights

130 into the molecular mechanisms of blue light-induced brown film formation at the PTM level.

131

132 Materials and Methods

\section{Materials treatment and protein extraction}

134 The L. edodes strain L901 which is a new hybrid strain was obtained from the Zhejiang

135 Academy of Agricultural Sciences. Fungal mycelia were grown at $22^{\circ} \mathrm{C}$ under red- and blue-light

136 conditions (LED light sources) for $22 \mathrm{~d}$. The light intensity approximately 100 lux and the

137 incubator illuminated all day. Fungal mycelia were grown were grown in the potato dextrose 
138 agar media. Samplings were taken after mycelial changed colour under blue light conditions. The

139 determination of total polysaccharides was performed according to Zhang's description (Zhang et

140 al. 2018). For protein extraction, a proper amount of sample was ground in liquid nitrogen into a

141 cellular powder and then transferred to a 5-mL centrifuge tube. The samples were treated with

142 four volumes of lysis buffer (10 mM dithiothreotol, 1\% protease inhibitor, and 1\% phosphatase

143 inhibitor) and then sonicated three times. The supernatant was centrifuged for 10 min at $4^{\circ} \mathrm{C}$ and

$1445,500 \mathrm{~g}$ with an equal volume of Tris equilibrium phenol. The supernatant was taken and

145 precipitated overnight with a fivefold volume of $0.1 \mathrm{M}$ ammonium acetate/methanol. The protein

146 precipitation was washed sequentially with methanol and acetone. The protein was redissolved in

$1478 \mathrm{M}$ urea, and the protein concentration was determined using a bicinchoninic acid assay kit

148 (P0012, Beyotime, Shanghai, China) according to the manufacturer's instructions.

149 Trypsin digestion, TMT labeling, and HPLC fractionation

150 For digestion, the final concentration of dithiothreotol in the protein solution was $5 \mathrm{mM}$ and was

151 reduced at $56^{\circ} \mathrm{C}$ for $30 \mathrm{~min}$. The $11-\mathrm{m}$ final concentration of iodoacetamide was incubated at

152 room temperature for $15 \mathrm{~min}$. Finally, the urea concentration of the sample was diluted to less

153 than $2 \mathrm{M}$. Trypsin was added at 1:50 trypsin-to-protein mass ratio for the first digestion

154 overnight and 1:100 trypsin-to-protein mass ratio for a second $4 \mathrm{~h}$-digestion. The trypsinase-

155 hydrolyzed peptide segments were desalted using a Strata X C18 (Phenomenex) and then freeze-

156 dried in a vacuum. The peptide segment was dissolved in $0.5 \mathrm{M}$ Triethylammonium bicarbonate

157 and labeled according to the instructions of the TMT kit(90066, Thermo-Scientific, Rockford, IL,

158 USA). The simple operation was as follows: the labeled reagent was dissolved in acetonitrile

159 after thawing, incubated at room temperature for $2 \mathrm{~h}$ after mixing with the peptide segment,

160 desalinated after mixing with the labeled peptide segment, and freeze-dried in a vacuum.

161 The tryptic peptides were fractionated using high $\mathrm{pH}$ reverse-phase HPLC on an Agilent

162 300Extend C18 column (5- $\mu$ m particles, 4.6-mm ID, 250-mm length). Briefly, peptides were first

163 separated using a gradient of $8 \%$ to $32 \%$ acetonitrile ( $\mathrm{pH} 9.0$ ) over 60 min into 60 fractions.

164 Then, the peptides were combined into six fractions and dried by vacuum centrifugation. 


\section{Affinity enrichment}

167 Peptide mixtures were first incubated with an immobilized metal ion affinity chromatography 168 (IMAC) microsphere suspension and vibrated in loading buffer (50\% acetonitrile and 6\% 169 trifluoroacetic acid). IMAC microspheres were used Ti. The IMAC microspheres enriched with

170 phosphopeptides were collected by centrifugation, and the supernatant was removed. To remove 171 nonspecifically adsorbed peptides, the IMAC microspheres were washed with loading buffer and $17230 \%$ acetonitrile plus $0.1 \%$ trifluoroacetic acid, sequentially. To elute the enriched 173 phosphopeptides from the IMAC microspheres, elution buffer containing $10 \% \mathrm{NH}_{4} \mathrm{OH}$ was 174 added, and the enriched phosphopeptides were eluted with vibration. The resulting peptides were 175 desalted with C18 ZipTips (Millipore) and lyophilized for the LC-MS/MS analysis.

\section{LC-MS/MS analysis}

178 The tryptic peptides were dissolved in $0.1 \%$ formic acid and directly loaded onto a home-made 179 reversed-phase analytical column (15-cm length and 75- $\mu \mathrm{m}$ i.d.). The gradient increased from $1806 \%$ to $23 \%$ solvent B ( $0.1 \%$ formic acid in $98 \%$ acetonitrile) over $26 \mathrm{~min}, 23 \%$ to $35 \%$ in $8 \mathrm{~min}$ 181 and to $80 \%$ in $3 \mathrm{~min}$. It was then held at $80 \%$ for the last $3 \mathrm{~min}$, at a constant flow rate of 400 $182 \mathrm{~nL} / \mathrm{min}$ on an EASY-nLC 1000 UPLC system.

183 The peptides were subjected to an NSI source followed by MS/MS in Q ExactiveTM Plus 184 (Thermo) coupled online to the UPLC. The electrospray voltage applied was $2.0 \mathrm{kV}$. The m/z scan range was 350 to 1,800 for a full scan, and intact peptides were detected in the Orbitrap at a resolution of 70,000. Peptides were then selected for MS/MS using normalized collision energy (NCE) set as 28, and the fragments were detected in the Orbitrap at a resolution of 17,500. The data-dependent procedure alternated between one MS scan and $20 \mathrm{MS} / \mathrm{MS}$ scans with a 15.0-s dynamic exclusion. The automatic gain control was set at 5E4. The fixed first mass was set as

$190100 \mathrm{~m} / \mathrm{z}$.

\section{Database search}

193 The MS data were retrieved using Maxquant (v1.5.2.8) using the following search parameter 194 settings: the database was Lentinula_edodes_uniprot

195 (https://www.uniprot.org/proteomes/?query=organism:5353\&sort=score); an anti-database was 
196 added to calculate the false positive rate (FDR) caused by random matching and a common

197 contamination library was added to eliminate the contamination proteins from the results.

198 Trypsin/P was specified as the cleavage enzyme, allowing up to four missing cleavage events.

199 The mass tolerance for precursor ions was set as $20 \mathrm{ppm}$ in the first search and $5 \mathrm{ppm}$ in the main

200

201

202

203

204

205

206

207

208

209

210

211

212

213

214

215

216

217

218

219

220

221

222

223

224

225

\section{Annotation methods and functional enrichment}

The GO annotation on the proteomics level was derived from the UniProt-GOA database (http://www.ebi.ac.uk/GOA/). First, the system converted the protein ID to UniProt ID, matched the GO ID with the UniProt ID, and then extracted the corresponding information from the UniProt-GOA database based on the GO ID. If there was no protein information queried in the UniProt-GOA database, then algorithm software based on the protein sequence, InterProScan, was used to predict the GO function of the protein.

The KEGG database was used to annotate protein pathways. First, the KEGG online service tool KAAS was used to annotate the submitted proteins, and then KEGG mapper was used to place the annotated proteins into the corresponding pathways in the database. WoLF PSORT, a software for predicting subcellular localization, was used to annotate the submitted proteins for subcellular localization. Fisher's exact test was used to detect differentially modified proteins against the background of identified proteins. A P-value of less than 0.05 was considered significant. The softwares motif-x and MoMo were used to analyze the models of sequences that contained the amino acids in specific positions of modified 13-mers (six amino acids upstream and downstream of the site) in all the protein sequences.

\section{Results}

Characteristics of quantitative phosphoproteomic data in $L$. edodes mycelia Using affinity enrichment followed by LC-MS/MS, the phosphoproteomic changes in L. edodes mycelia grown in red or blue light were investigated. A flow chart of our experiment is exhibited 
226 in Fig.1A. Pearson's correlation coefficient between the two groups showed sufficient 227 reproducibility (Fig. 1B). In this study, 160,949 secondary spectra were obtained by MS

228 analyses. After searching the theoretical protein data, the effective number of spectra was 22,857

229 and the utilization rate of the spectra was $14.2 \%$. In total, 8,830 peptides and 7,777

230 phosphorylated peptides were identified. There were 11,224 phosphorylation modification sites

231 on 2,786 proteins, of which 9,243 sites on 2,579 proteins provided quantitative information

232 (Fig.1C). The first-order mass errors of most spectra are less than $10 \mathrm{ppm}$, which is in

233 accordance with the high accuracy of the MS (Fig. 1D). Most of the peptides were distributed in

234 7-20 amino acids, which was in accordance with the general rules of trypsin-based enzymatic

235 hydrolysis and high energy collision dissociation (HCD) fragmentation, indicating that the

236 sample preparation and the quality accuracy of the mass spectrometer reached the standard

237 required(Fig.1E). The detailed information regarding the identified peptides are listed in Table

238 S1.

\section{Analysis of phosphorylation sites}

241 In L. edodes mycelia, 977 (35.07\%) phosphoproteins were modified at a single site, 519

$242(18.63 \%)$ at two sites, and 1,290 (46.3\%) at three or more phosphosites (Fig.2A). Interestingly,

243 some proteins contained a large number of phosphosites. For example, there are 34 phosphosites

244 in a non-specific serine/threonine protein kinase (A0A1Q3E061), 45 phosphosites in a regulatory

245 transcript from a polymerase II promoter-related protein (A0A1Q3ERS8) and 53 phosphosites in

246 a SRC Homology 3 (Sh3) domain-containing protein (A0A1Q3ENM7)( Table S1).

247 To analyze the density levels of the phosphorylation sites in each protein, the phosphorylated

248 proteome of L. edodes was compared with those of other species. The average number of

249 phosphorylation sites per protein in L. edodes is 3.22, which is similar to the numbers in Bombyx

250 mori (3.07), Nicotiana tabacum (3.05), and Physcomitrella patens (3.44) (Fig.2B)(Fang et al.

251 2016; Lu et al. 2019; Shobahah et al. 2017).

\section{Characteristics of the identified phosphoproteins in L. edodes}

253 To predict the possible functions of the identified phosphoproteins, a GO classification analysis

254 was performed. Most of the proteins were classified into three GO categories(Fig. 3A).

255 Specifically, 594 proteins were annotated as 'metabolic process', 519 proteins were annotated as

256 'cellular process', and 361 proteins were annotated as 'single-organism process'. In the cellular 
257

258

259

260

261

262

263

264

265

266

267

268

269

270

271

272

273

274

275

276

277

278

279

280

281

282

283

\section{4}

285

286

287

component category, the largest terms were 'cell' (289 proteins), 'organelle' (186 proteins), and 'macromolecular complex' (154 proteins). In the molecular function category, 'binding' (846 proteins), 'catalytic activity' (627 proteins), and 'transporter activity' (51 proteins) were the three top dominant terms. The euKaryotic Ortholog Groups annotation clustered all the phosphoproteins into four major categories. The 'cellular processes and signaling' category contained the largest number of proteins(Fig.3B). Most identified phosphoproteins were grouped into 13 subcellular component categories predicted by WoLF PSORT software, including 783 nuclear, 380 cytoplasmic, and 275 mitochondrial proteins(Fig.3C). The detailed annotation information for all the identified phosphoproteins are listed in Table S2.

\section{Protein motifs associated with phosphorylation}

Among the identified phosphosites in L. edodes, 8,645 sites occurred at serine residues, 2239 sites at threonine residues, and 340 sites at tyrosine residues (Fig.4A). To understand the upstream pathway of the identified phosphorylated proteins, a motif analysis was carried out using MOMO and Motif-X software. A number of conserved phosphorylation motifs were enriched in the phosphorylated proteins of $L$. edodes (Table S3). A total of 7,741 distinct sequences containing 13 residues were obtained, with 6 upstream and 6 downstream residues around each phosphosite (Table S4). The five S-based motifs containing the largest numbers of sequences were 'sP', 'RxxsP', PxsP' 'Gs', and 'RRxS', and the five top T-based motifs were 'tP', 'tPP', 'RxxtP', RxtP', and 'Rxxt'. A Y-based motif, 'Rxxxxxy', was identified. Two position-specific heat maps of upstream and downstream amino acids at all the identified phosphorylated serine or threonine sites. For the S-based motifs, strong preferences for glutamic acid, lysine, and arginine upstream, and aspartic acid, glutamic acid, and proline downstream, of the phosphorylation sites were observed. For the T-based motifs, preferences for lysine, proline, and arginine upstream, and aspartic acid and proline downstream, of the phosphorylation sites were observed (Fig. 4C).

\section{Differentially phosphorylated proteins (DPPs) in response to a blue-light treatment}

To compare the DPPs between red- and blue-light treated samples, expression profiles of the proteins generated by MeV software are shown in a heatmap (Fig. 5A). The screening of DPPs followed the following criteria: change threshold $\geq 1.5$ times and t-test $p$-value $<0.05$. Among

Peer] reviewing PDF | (2020:03:47263:1:1:NEW 22 Jul 2020) 
288

289

290

291

292

293

294

295

296

297

298

299

300

301

302

303

304

305

306

307

308

309

310

311

312

313

315

316

317

314 Identification of DPPs related to signal transduction mechanisms and carbohydrate-active

these DPPs, 475 sites in 317 phosphorylated proteins were up-regulated and 349 sites in 243 phosphorylated proteins were down-regulated (Fig. 5B and Table S5). Based on the subcellular localizations predicted by WoLF PSORT software, all the DPPs were classified into 10 subcellular components. There were 204 nuclear localized DPPs, 82 cytoplasmic localized DPPs, and 51 plasma membrane localized DPPs (Fig. 5C).

\section{Functional enrichment analysis of the DPPs}

To understand the biological functions of these phosphorylated proteins, GO, KEGG and protein domain enrichment analyses of DPPs were carried out. For biological process, cellular component, and molecular function categories, the DPPs were mostly enriched in 'DNA conformation change' (Fig. 6A); 'nucleosome' (Fig. 6B), and 'transporter activity' (Fig. 6C), respectively.

To reveal the metabolic pathways involved in the formation of brown films induced by blue light, the DPPs were further analyzed using the KEGG database. For the up-regulated DPPs, two KEGG pathways, 'Ribosome biogenesis in eukaryotes', and 'ABC transporters', were significantly enriched' (Fig. 7A). For the down-regulated DPPs, four enriched KEGG pathways were identified, 'Valine, leucine and isoleucine degradation', 'Phenylalanine metabolism', 'Galactose metabolism', and 'Fructose and mannose metabolism' (Fig. 7B). We also found that the total polysaccharides of blue light treatment was significantly lower than that of red light treatment (Fig. S1). A protein domain enrichment analysis revealed that the up-regulated DPPs were enriched in 19 protein domains, with 'ABC transporter-like', 'P-type ATPase', and 'HADlike domain' being the most highly enriched(Fig. 7C). The down-regulated DPPs were most strongly associated with 'Glutathione S-transferase, C-terminal-like', 'YTH domain' 'VPS9 domain', 'Domain of unknown function DUF1708', and 'High mobility group box domain'(Fig. 7D). enzymes (CAZymes)

16 To better understand the DPPs related to blue light-induced mycelial brown film formation, a functional classification of DPPs was conducted using euKaryotic Ortholog Groups. A total of 
318319 DDPs were grouped into 23 subcategories (Fig. S2). For the 'signal transduction

319 mechanisms' subcategory, 50 phosphosites in 29 phosphorylated proteins were identified (Table

320 1). Among these, 30 phosphosites were up-regulated and 20 were down-regulated.

321 CAZymes, including auxiliary activity (AA), carbohydrate-binding modules (CBM),

322 carbohydrate esterase (CE), glycoside hydrolase (GH), glycosyl transferase (GT), and

323 polysaccharide lyase (PL), were involved in the hydrolysis of plant cell wall polysaccharides and

324 play an important role in the degradation of substrates(Davies \& Williams 2016). In the present

325 study, 13 DPPs were identified as CAZymes, including 11 phosphosites in three CBMs, two

326 phosphosites in two CEs, four phosphosites in three GHs, and six phosphosites in five GTs(Table

327 2). Interestingly, the GHs were up-regulated, while the CBMs were down-regulated.

328

329 Discussion

330 With the completion of various biological genome sequences, proteomics has become an

331 increasingly important analysis of important proteins based on the differential recognition of

332 their expression levels. Protein phosphorylation is an important PTM, which can rapidly control

333 enzyme activity, subcellular localization, and protein stability, and involves the regulation of

334 metabolism, transcription, and translation, as well as protein degradation, homeostasis, cell

335 signaling, and communication(Lv et al. 2014; Thingholm et al. 2009; Yu et al. 2019). Recently,

336 large-scale quantitative phosphoproteomics analyses were performed in many plants to elucidate

337 the growth, development, and diverse response mechanisms, but the technology has rarely been

338 applied to L. edodes(Lv et al. 2014). Here, we report a comprehensive analysis of

339 phosphoproteomic responses to blue light-induced mycelial brown film formation of L. edodes

340 through a combination of affinity enrichment and LC-MS/MS.

341 Protein phosphorylation is a common PTM, but the level of phosphorylation varies with

342 species., The number of phosphorylation sites in each protein is 3.22, which is higher than most

343 published phosphorylation proteomes, indicating that the degree of phosphorylation in the $L$.

344 edodes proteome is very high. The large number of identified phosphoproteins provide an

345 opportunity to comprehensively analyze the mechanism of blue light-induced mycelial brown

346 film formation. The 'sP' motif most frequently occurred in many species, including $L$.

347 edodes(van Wijk et al. 2014; Wang et al. 2014; Zhang et al. 2014). 'sP' is a target of the

348 following kinases: cyclin-dependent kinase, mitogen-activated protein kinase (MAPK), and 
349 sucrose non-fermenting1-related protein kinase 2(van Wijk et al. 2014; Zhang et al. 2014). The

350 'tP'motif also provides a target for MAPKs(Wang et al. 2013).

351 In Basidiomycetes, light is a crucial environmental factor that affects fruiting body induction 352 and development(Kues 2000; Kues \& Liu 2000). In recent years, in fungi, the effects of different 353 light wavelengths on mycelial morphology, metabolites, and enzymatic activities have been 354 studied. In Monascus, red and blue light can affect the formation of mycelia and spores, as well 355 as the production of secondary metabolites(Miyake et al. 2005). In this study, we found that blue 356 light can promote the formation of a brown film associated with $L$. edodes mycelia, but no 357 correlation was found with a red-light treatment. The effects of blue light on the expression 358 levels of phosphorylated proteins during brown film formation were studied. Phosphorylation 359 proteomics revealed that 560 phosphorylated proteins were differentially expressed during a 360 blue-light treatment.

361 Brown film formation at the transcriptional level is correlated with photoreceptor activity, 362 light signaling pathways, and pigment formation(Tang et al. 2013). Most fungi perceive blue

363 light through homologues of the white collar complex, which is a complex of photoreceptors and 364 transcription factors that was first found in Neurospora crassa(Tagua et al. 2015). The N-

365 terminus of WC-1 is a lov domain, which is a special Per-Arnt-Sim (PAS) domain that can bind 366 to flavin adenine dinucleotide(Crosson et al. 2003). Light sensing via photoreceptors such as 367 FMN- and FAD-bindings and signal transduction by kinases and G protein-coupled receptors 368

369 phenotypes(Yoo et al, 2019). In the present study, three flavin adenine dinucleotide-binding 370 domains and an FMN-binding domain differentially accumulated, indicating that the L. edodes 371 mycelia could have perceived blue light when the brown film was formed. The MAPK cascade is 372 an important signal transduction pathway connecting light responses and the biological clock(de 373 Paula et al. 2008). MAPK also regulates various secondary metabolic activities in Aspergillus 374 nidulans and Colletotrihum lagenarium, and it controls light-influenced melanin biosynthesis in 375 B. cinerea(Atoui et al. 2008; Bayram \& Braus 2012; Liu et al. 2011; Takano et al. 2000). The 376 MAPK signal transduction pathways may be directly involved in brown film formation(Tang et 377 al. 2013). Several MAPK signal transduction pathways related to DPPs were identified in this 378 study, suggesting that these signal pathways are involved in the formation of brown films.

379 The differential expression of CAZymes were observed in L. edodes mycelia under two light 380 conditions. GHs mainly hydrolyze glycosidic bonds between carbohydrates or between 
381 carbohydrates and non-carbohydrates(Sathya \& Khan 2014). The GH61 family contains copper-

382 dependent lytic polysaccharide monooxygenase(Langston et al. 2011). CEs catalyze the

383 deacylation of esters or amides, in which sugar plays the role of alcohol and amine(Biely 2012;

384 Vidal-Melgosa et al. 2015). They are currently divided into 16 different families, which have a

385

386

387

388

389

390

391

392

393

394

395

396

397

398

399

400

401

402

403

404

405

406

407

408

409

410

411

412

413 great diversity in substrate specificity and structure(Vidal-Melgosa et al. 2015). CE10 (two DPPs) were down-regulated by blue light. CBMs are noncatalytic, individually folded domains that are attached to the catalytic enzyme modules by linkers(Varnai et al. 2014). Some CE1 enzymes may contain a CBM48 family protein, which is associated with starch binding(Wilkens et al. 2017; Wong et al. 2017). Our research showed that these CAZymes play important roles in the degradation of lignocellulose and provide sufficient nutrition for the formation of the brown film of mushroom mycelia.

To survive, fungi have evolved the ability to adapt to different environmental conditions, and various metabolic pathways secrete different metabolites( $Y u \&$ Keller 2005). The regulation of these metabolites is not only related to fungal growth and development, but also to light stimulation and responses. The shorter the light wavelength, the more polysaccharides accumulated in the cells of Pleurotus eryngii(Jang et al. 2011). Blue-light treatments significantly improved the synthesis of ergosterol and polyphenols in the fruiting body of Pleurotus eryngii, and the scavenging ability of the free radicals was the greatest compared with other light treatments(Jang et al. 2011). In our study, the KEGG-enrichment analysis showed that four DPPs belonged to 'Galactose metabolism' and 'Fructose and mannose metabolism', suggesting that the blue light affected the sugar metabolism of L. edodes. Phenolic compounds were correlated with pigment formation(Weijn et al. 2013). Phenylalanine ammonia-lyase and tyrosinase-encoding genes were significantly up-regulated in $P$. eryngii under blue-light conditions(Du et al. 2019). Two 'Phenylalanine metabolism' pathway phosphoproteins, amidase (A0A1Q3E9W2) and aspartate aminotransferase (A0A1Q3EG41), were down-regulated in mycelia under blue-light conditions. These results suggested that blue light may promote the formation of melanin and inhibit the formation of other phenolic compounds. Polyketide synthase $(\mathrm{PKS})$ is an essential enzyme in the biosynthesis of fungal secondary metabolites(Austin \& Noel 2003; Linnemannstons et al. 2002). PKSs modify the polyketide backbone with other enzymes, such as Cytochrome P450 monooxygenases, oxidoreductase, and omethyltransferase(Austin \& Noel 2003). P450-linked monooxygenases mediate oxidationreduction steps in aflatoxin biosynthesis, and omethyltransferase was involved in yellow pigment biosynthesis through an aflatoxigenic Aspergillus strain(Bhatnagar et al. 2003). In our study, the 
414 phosphorylation levels of PKS, O-methyltransferase, P450 monooxygenase, and oxidoreductase

415 changed in brown film formation, indicating that they may play roles in pigment production.

416 The ABC transport family is widely distributed in all living species, including several

417 subfamilies, which are responsible for different types of material transport

418 (Higgins.2001;Holland and Blight. 1999). ATPase is the largest ATP dependent ion transporter

419 in organisms, transporting many different ions, metals and other substrates (Palmgren \& Nissen,

420 2011). Two VPS9 domain containing proteins, Rab5 GDP/GTP exchange factor, were down-

421 regulated under blue light treatment. Studies have shown that the transport of endocytic vesicles

422 is partially regulated by Rab protein (Zhu et al, 2018). Rab protein needs to be activated by

423 guanine nucleotide exchange factor, which transforms Rab from a GDP binding state to a GTP

424 binding state(Zerial,2001). The changed in these proteins suggest that blue light altered the

425 transport of certain substances. In mushrooms, blue light can promote growth, which is

426 considered to be an important environmental factor affecting the growth of fruiting bodies(Yoo et

427 al, 2019).In this study, ribosome biogenesis related proteins were observed to be up-regulated

428 under blue light treatment.

429

430 Conclusions

431 Using a high-resolution LC-MS/MS integrated with a highly sensitive immune-affinity antibody

432 method, phosphoproteomes of $L$. edodes mycelia under red- and blue-light conditions were

433 analyzed. In this study, 11,224 phosphorylation sites were identified on 2,786 proteins, of which

4349,243 sites on 2,579 proteins contained quantitative information. In total, 475 sites were up-

435 regulated and 349 sites were down-regulated in the blue vs red group. Then, we carried out a

436 systematic bioinformatics analyses of proteins containing quantitative information sites,

437 including protein annotations, functional classifications, and functional enrichments. Our study

438 provides new insights into the molecular mechanisms of the blue light-induced brown film

439 formation at the PTM level

440

\section{Acknowledgments}

442 We are grateful to the PTM Biolabs company for technical support. We thank International

443 Science Editing for editing this manuscript(http://www.internationalscienceediting.com ) 


\section{ADDITIONAL INFORMATION AND DECLARATIONS}

446

\section{Funding}

448 This study was supported by the Zhejiang Science and Technology Major program on

449 Agriculture New Variety Breeding (Grant No.2016C02057) and National Science Foundation of 450 Zhejiang Province of China (Grant No.LQ16C150004). The funders had no role in study design, 451 data collection and analysis, decision to publish, or preparation of the manuscript.

\section{Grant Disclosures}

454 The following grant information was disclosed by the authors:

455 Zhejiang Science and Technology Major program on Agriculture New Variety Breeding: $4562016 \mathrm{C} 02057$.

457 National Science Foundation of Zhejiang Province of China: Grant No.LQ16C150004.

458

\section{Competing interests}

460 The authors declare that they have no competing interests.

461

\section{Author Contributions}

463 - Tingting Song and Weiming Cai conceived and designed the experiments, performed the

464 experiments,analyzed the data, prepared figures and/or tables, authored or reviewed drafts of the 465 paper, approved the final draft.

466 - Yingyue Shen and Qunli Jin Weilin Feng performed the experiments, analyzed the 467 data, approved the final draft. 
468 - Weilin Feng and Lijun Fan performed the experiments, analyzed the data, prepared figures 469 and/or tables, approved the final draft, comparative experimental data.

470

471

Data Availability

472 The following information was supplied regarding data availability:

473 The raw data is available at ProteomeXchange:PXD016536

474

475

\section{References}

476

477

478

479

480

481

482

483

484

485

486

487

488

489

490

491

492

493

Abbott A. 2001. And now for the proteome. Nature 409:747-747.

Aleksandrova EA, Zav'yalova LA, Tereshina VM, Garibova LV, and Feofilova EP. 1998. Obtaining of fruiting bodies and submerged mycelium of Lentinus edodes (Berk.) Sing [Lentinula edodes (Berk.) Pegler]. Microbiology 67:535-539.

Atoui A, Bao DP, Kaur N, Grayburn WS, and Calvo AM. 2008. Aspergillus nidulans natural product biosynthesis is regulated by $\mathrm{mpkB}$, a putative pheromone response mitogenactivated protein kinase. Applied And Environmental Microbiology 74:3596-3600.

Austin MB, and Noel AJP. 2003. The chalcone synthase superfamily of type III polyketide synthases. Natural Product Reports 20:79-110.

Bayram O, and Braus GH. 2012. Coordination of secondary metabolism and development in fungi: the velvet family of regulatory proteins. Fems Microbiology Reviews 36:1-24.

Bhatnagar D, Ehrlich KC, and Cleveland TE. 2003. Molecular genetic analysis and regulation of aflatoxin biosynthesis. Applied Microbiology and Biotechnology 61:83-93.

Biely P. 2012. Microbial carbohydrate esterases deacetylating plant polysaccharides. Biotechnology Advances 30:1575-1588.

Casas-Flores S, Rios-Momberg M, Rosales-Saavedra T, Martinez-Hernandez P, Olmedo-Monfil V, and Herrera-Estrella A. 2006. Cross talk between a fungal blue-light perception system and the cyclic AMP signaling pathway. Eukaryotic Cell 5:499-506. 
494 Chum WW, Ng KT, Shih RS, Au CH, and Kwan HS. 2008. Gene expression studies of the

495

496

497

498

499

500

501

502

503

504

505

506

507

508

509

510

511

512

513

514

515

516

517

518

519

520

521 dikaryotic mycelium and primordium of Lentinula edodes by serial analysis of gene expression. Mycol Res 112:950-964.

Cohen Y, Vaknin M, Ben-Naim Y, and Rubin AE. 2013. Light Suppresses Sporulation and Epidemics of Peronospora belbahrii. Plos One 8.

Crosson S, Rajagopal S, and Moffat K. 2003. The LOV domain family: Photoresponsive signaling modules coupled to diverse output domains. Biochemistry 42:2-10.

Davies GJ, and Williams SJ. 2016. Carbohydrate-active enzymes: sequences, shapes, contortions and cells. Biochemical Society Transactions 44:79-87.

de Paula RM, Lamb TM, Bennett L, and Bell-Pedersen D. 2008. A connection between MAPK pathways and circadian clocks. Cell Cycle 7:2630-2634.

Du F, Zou Y, Hu Q, Zhang H, and Ye D. 2019. Comparative transcriptomic analysis reveals molecular processes involved in pileus morphogenesis in Pleurotus eryngii under different light conditions. Genomics.

Dunlap JC. 2006. Proteins in the Neurospora circadian clockworks. Journal Of Biological Chemistry 281:28489-28493.

Fang Y, Zhang Q, Wang X, Yang X, Wang XY, Huang Z, Jiao YC, and Wang J. 2016. Quantitative phosphoproteomics reveals genistein as a modulator of cell cycle and DNA damage response pathways in triple-negative breast cancer cells. International Journal of Oncology 48:1016-1028.

Graves PR, and Haystead TAJ. 2002. Molecular biologist's guide to proteomics. Microbiology And Molecular Biology Reviews 66:39-+.

Hernandez-Macedo ML, Ferraz A, Rodriguez J, Ottoboni LMM, and De Mello MP. 2002. Ironregulated proteins in Phanerochaete chrysosporium and Lentinula edodes: Differential analysis by sodium dodecyl sulfate polyacrylamide gel electrophoresis and twodimensional polyacrylamide gel electrophoresis profiles. Electrophoresis 23:655-661.

Higgins CF. 2001. ABC transporters: physiology, structure and mechanism - an overview. Research in Microbiology 152:0-210. 
522 Holland IB, and Blight MA. 1999. ABC-ATPases, adaptable energy generators fuelling

523

524

525

526

527

528

529

530

531

532

533

534

535

536

537

538

539

540

541

542

543

544

545

546

547

548 transmembrane movement of a variety of molecules in organisms from bacteria to humans. Journal of Molecular Biology 293:0-399.Hurley JM, Chen CH, Loros JJ, and Dunlap JC. 2012. Light-Inducible System for Tunable Protein Expression in Neurospora crassa. G3-Genes Genomes Genetics 2:1207-1212.

Jang MJ, Lee YH, Kim JH, and Ju YC. 2011. Effect of LED Light on Primordium Formation, Morphological Properties, Ergosterol Content and Antioxidant Activity of Fruit Body in Pleurotus eryngii. Korean Journal of Mycology 39.

Kim JY, Kim DY, Park YJ, and Jang MJ. 2020. Transcriptome analysis of the edible mushroom Lentinula edodes in response to blue light. Plos One 15:e0230680.

Koo CD, Lee SJ, and Lee HY. Morphological Characteristics of Decomposition and Browning of Oak Sawdust Medium for Ground Bed Cultivation of Lentinula edodes.

Kues U. 2000. Life history and developmental processes in the basidiomycete Coprinus cinereus. Microbiology And Molecular Biology Reviews 64:316-+.

Kues U, Granado JD, Hermann R, Boulianne RP, Kertesz-Chaloupkova K, and Aebi M. 1998. The A mating type and blue light regulate all known differentiation processes in the basidiomycete Coprinus cinereus. Molecular And General Genetics 260:81-91.

Kues U, and Liu Y. 2000. Fruiting body production in basidiomycetes. Applied Microbiology and Biotechnology 54:141-152.

Kuratani M, Tanaka K, Terashima K, Muraguchi H, Nakazawa T, Nakahori K, and Kamada T. 2010. The dst 2 gene essential for photomorphogenesis of Coprinopsis cinerea encodes a protein with a putative FAD-binding-4 domain. Fungal Genetics And Biology 47:152-158.

Langston JA, Shaghasi T, Abbate E, Xu F, Vlasenko E, and Sweeney MD. 2011. Oxidoreductive Cellulose Depolymerization by the Enzymes Cellobiose Dehydrogenase and Glycoside Hydrolase 61. Applied And Environmental Microbiology 77:7007-7015.

Liang Y, Chen H, Tang MJ, and Shen SH. 2007. Proteome analysis of an ectomycorrhizal fungus Boletus edulis under salt shock. Mycol Res 111:939-946. 
549 Linden, and $\mathrm{H}$. White collar 2, a partner in blue-light signal transduction, controlling expression of light-regulated genes in Neurospora crassa. Embo Journal 16:98-109.

551 Linnemannstons P, Schulte J, del Mar Prado M, Proctor RH, Avalos J, and Tudzynski B. 2002.

552

553

554

555

556

557

558

559

560

561

562

563

564

565

566

567

568

569

570

571

572

573

574

575

576 The polyketide synthase gene pks4 from Gibberella fujikuroi encodes a key enzyme in the biosynthesis of the red pigment bikaverin. Fungal Genetics And Biology 37:134-148.

Liu WW, Soulie MC, Perrino C, and Fillinger S. 2011. The osmosensing signal transduction pathway from Botrytis cinerea regulates cell wall integrity and MAP kinase pathways control melanin biosynthesis with influence of light. Fungal Genetics And Biology 48:377-387.

Lu ZS, Chen QS, Zheng QX, Shen JJ, Luo ZP, Fan K, Xu SH, Shen Q, and Liu PP. 2019. Proteomic and Phosphoproteomic Analysis in Tobacco Mosaic Virus-Infected Tobacco (Nicotiana tabacum). Biomolecules 9.

Lv DW, Li X, Zhang M, Gu AQ, Zhen SM, Wang C, Li XH, and Yan YM. 2014. Large-scale phosphoproteome analysis in seedling leaves of Brachypodium distachyon L. BMC Genomics 15.

Miyake T, Mori A, Kii T, Okuno T, Usui Y, Sato F, Sammoto H, Watanabe A, and Kariyama M. 2005. Light effects on cell development and secondary metabolism in Monascus. Journal Of Industrial Microbiology \& Biotechnology 32:103-108.

Ozcelik E, and Peksen A. 2007. Hazelnut husk as a substrate for the cultivation of shiitake mushroom (Lentinula edodes). Bioresource Technology 98:2652-2658.

Palmgren MG. Nissen P, 2011. P-type ATPases. Annu Rev Biophys, 40, pp. 243266Philippoussis A, Zervakis G, and Griensven LJLDV. 2000. Cultivation of edible mushrooms in Greece: presentation of the current status and analysis of future trends. 96:620-627.

Piehler J. 2005. New methodologies for measuring protein interactions in vivo and in vitro. Current Opinion In Structural Biology 15:4-14.

Sano H, Kaneko S, Sakamoto Y, Sato T, and Shishido K. 2009. The basidiomycetous mushroom Lentinula edodes white collar-2 homolog PHRB, a partner of putative blue-light 
577

578

579

580

581

582 583

584

585

586

587

588

589

590

591

592

593

594

595

596

597

598

599

600

601

602

603

604 605

photoreceptor PHRA, binds to a specific site in the promoter region of the L-edodes tyrosinase gene. Fungal Genetics And Biology 46:333-341.

Sano H, Narikiyo T, Kaneko S, Yamazaki T, and Shishido K. 2007. Sequence analysis and expression of a blue-light photoreceptor gene, Le.phrA from the basidiomycetous mushroom Lentinula edodes. Bioscience Biotechnology And Biochemistry 71:2206-2213.

Sathya TA, and Khan M. 2014. Diversity of Glycosyl Hydrolase Enzymes from Metagenome and Their Application in Food Industry. Journal Of Food Science 79:R2149-R2156.

Shobahah J, Xue SJ, Hu DB, Zhao C, Wei M, Quan YP, and Yu W. 2017. Quantitative phosphoproteome on the silkworm (Bombyx mori) cells infected with baculovirus. Virology Journal 14.

Tagua VG, Pausch M, Eckel M, Gutierrez G, Miralles-Duran A, Sanz C, Eslava AP, Pokorny R, Corrochano LM, and Batschauer A. 2015. Fungal cryptochrome with DNA repair activity reveals an early stage in cryptochrome evolution. Proceedings Of the National Academy Of Sciences Of the United States Of America 112:15130-15135.

Takano Y, Kikuchi T, Kubo Y, Hamer JE, Mise K, and Furusawa I. 2000. The Colletotrichum lagenarium MAP kinase gene CMK1 regulates diverse aspects of fungal pathogenesis. Molecular Plant-Microbe Interactions 13:374-383.

Tang LH, Jian HH, Song CY, Bao DP, Shang XD, Wu DQ, Tan Q, and Zhang XH. 2013. Transcriptome analysis of candidate genes and signaling pathways associated with lightinduced brown film formation in Lentinula edodes. Appl Microbiol Biotechnol 97:49774989.

Tang LH, Tan Q, Bao DP, Zhang XH, Jian HH, Li Y, Yang RH, and Wang Y. 2016. Comparative Proteomic Analysis of Light-Induced Mycelial Brown Film Formation in Lentinula edodes. Biomed Research International.

Terashima K, Yuki K, Muraguchi H, Akiyama M, and Kamada T. 2005. The dst1 gene involved in mushroom photomorphogenesis of Coprinus cinereus encodes a putative photoreceptor for blue light. Genetics 171:101-108.

Thingholm TE, Jensen ON, and Larsen MR. 2009. Analytical strategies for phosphoproteomics. Proteomics 9:1451-1468. 
606 Tsivileva OM, Pankratov AN, Nikitina VE, and Garibova LV. 2005. Effect of media components

607

608

609

610

611

612

613

614

615

616

617

618

619

620

621

622

623

624

625

626

627

628

629

630

631

632

633

634

on the mycelial film formation in submerged culture of Lentinus edodes (Shiitake). Food Technology And Biotechnology 43:227-234.

van Wijk KJ, Friso G, Walther D, and Schulze WX. 2014. Meta-Analysis of Arabidopsis thaliana Phospho-Proteomics Data Reveals Compartmentalization of Phosphorylation Motifs. Plant Cell 26:2367-2389.

Varnai A, Makela MR, Djajadi DT, Rahikainen J, Hatakka A, and Viikari L. 2014. Carbohydrate-Binding Modules of Fungal Cellulases: Occurrence in Nature, Function, and Relevance in Industrial Biomass Conversion. Advances In Applied Microbiology, Vol 88 88:103-165.

Vidal-Melgosa S, Pedersen HL, Schuckel J, Arnal G, Dumon C, Amby DB, Monrad RN, Westereng B, and Willats WGT. 2015. A New Versatile Microarray-based Method for High Throughput Screening of Carbohydrate-active Enzymes. Journal Of Biological Chemistry 290:9020-9036.

Wang K, Zhao Y, Li M, Gao F, Yang MK, Wang X, Li SQ, and Yang PF. 2014. Analysis of phosphoproteome in rice pistil. Proteomics 14:2319-2334.

Wang X, Bian YY, Cheng K, Gu LF, Ye ML, Zou HF, Sun SSM, and He JX. 2013. A largescale protein phosphorylation analysis reveals novel phosphorylation motifs and phosphoregulatory networks in Arabidopsis. Journal of Proteomics 78:486-498.

Weijn A, Bastiaan-Net S, Wichers HJ, and Mes JJ. 2013. Melanin biosynthesis pathway in Agaricus bisporus mushrooms. Fungal Genetics And Biology 55:42-53.

Wilkens C, Busk PK, Pilgaard B, Zhang WJ, Nielsen KL, Nielsen PH, and Lange L. 2017. Diversity of microbial carbohydrate-active enzymes in Danish anaerobic digesters fed with wastewater treatment sludge. Biotechnology for Biofuels 10.

Wong MT, Wang WJ, Couturier M, Razeq FM, Lombard V, Lapebie P, Edwards EA, Terrapon N, Henrissat B, and Master ER. 2017. Comparative Metagenomics of Cellulose- and Poplar Hydrolysate-Degrading Microcosms from Gut Microflora of the Canadian Beaver (Castor canadensis) and North American Moose (Alces americanus) after Long-Term Enrichment. Frontiers In Microbiology 8.

Peer) reviewing PDF | (2020:03:47263:1:1:NEW 22 Jul 2020) 
635 Wu JY, Chen HB, Chen MJ, Kan SC, Shieh CJ, and Liu YC. 2013. Quantitative analysis of LED 636 effects on edible mushroom Pleurotus eryngii in solid and submerged cultures. Journal Of Chemical Technology And Biotechnology 88:1841-1846.

638 Xie CL, Gong WB, Zhu ZH, Yan L, Hu ZX, and Peng YD. 2018. Comparative transcriptomics 639 of Pleurotus eryngii reveals blue-light regulation of carbohydrate-active enzymes (CAZymes) expression at primordium differentiated into fruiting body stage. Genomics 110:201-209.

Yang C, Ma L, Ying Z, Jiang X, and Lin Y. Sequence Analysis and Expression of a Blue-light Photoreceptor Gene,Slwc-1 from the Cauliflower MushroomSparassis latifolia. Current Microbiology 74:469-475.

Yang F, Xu B, Zhao SJ, Li JJ, Yang YJ, Tang XH, Wang F, Peng MZ, and Huang ZX. 2012. De novo sequencing and analysis of the termite mushroom (Termitomyces albuminosus) transcriptome to discover putative genes involved in bioactive component biosynthesis.

Yin J, Xin XD, Weng YJ, and Gui ZZ. 2017. Transcriptome-wide analysis reveals the progress 650 of Cordyceps militaris subculture degeneration. Plos One 12.

651

652

653

654

655

656 657

Yoo SI, Lee HY, Markkandan K, Moon S, Ahn YJ, Ji S, Ko J, Kim SJ, Ryu H, and Hong CP. 2019. Comparative transcriptome analysis identified candidate genes involved in mycelium browning in Lentinula edodes. BMC Genomics 20:121.Yu CL, Wu QF, Sun CD, Tang ML, Sun JW, and Zhan YH. 2019. The Phosphoproteomic Response of Okra (Abelmoschus esculentus L.) Seedlings to Salt Stress. International Journal Of Molecular Sciences 20.

Yu JH, and Keller N. 2005. Regulation of secondary metabolism in filamentous fungi. Annual Review Of Phytopathology 43:437-458.

Zerial M, and McBride H. 2001. Rab proteins as membrane organizers . Nature Reviews Molecular Cell Biology 2:216-216.

Zhan Y, Wu Q, Chen Y, Tang M, Sun C, Sun J, and Yu C. 2019. Comparative proteomic analysis of okra (Abelmoschus esculentus L.) seedlings under salt stress. 20:381. 
662 Zhang CH, Dong WQ, Gen W, Xu BY, Shen CJ, and Yu CL. 2018. De Novo Transcriptome

663

664

665

666

667

668

669

670

671

672

673

674

675

676

677

678

679

680

681

682
Assembly and Characterization of the Synthesis Genes of Bioactive Constituents in Abelmoschus esculentus (L.) Moench. Genes 9:16.

Zhang JJ, Chen H, Chen MJ, Ren A, Huang JC, Wang H, Zhao MW, and Feng ZY. 2015. Cloning and functional analysis of a laccase gene during fruiting body formation in Hypsizygus marmoreus. Microbiological Research 179:54-63.

Zhang M, Ma CY, Lv DW, Zhen SM, Li XH, and Yan YM. 2014. Comparative Phosphoproteome Analysis of the Developing Grains in Bread Wheat (Triticum aestivum L.) under Well-Watered and Water-Deficit Conditions. Journal Of Proteome Research $13: 4281-4297$.

Zhang XW, Li PR, Wang CL, Chen MH, Li ZJ, and Wang YR. 2013. Effect of Blue Light on the Growth, Culture Morphology, and Pigment Production of Monascus. Journal Of Pure And Applied Microbiology 7:671-678.

Zhou H, Ye M, Dong J, Corradini E, Cristobal A, Heck AJ, Zou H, and Mohammed S. 2013. Robust phosphoproteome enrichment using monodisperse microsphere-based immobilized titanium (IV) ion affinity chromatography. Nat Protoc 8:461-480.

Zhu XM, Liang S, Shi HB, Lu JP, Dong B, Liao QS, Lin FC, and Liu XH. 2018. VPS9 domaincontaining proteins are essential for autophagy and endocytosis in Pyricularia oryzae. Environ Microbiol 20:1516-1530. 


\section{Figure 1}

Figure 1 Overview of the phosphorylation proteomes.

(A) The pictures showed the fungal mycelia under different illumination for 22 days.

Experimental strategy for the quantitative analysis of phosphorylation proteomes from red and blue light treatment groups. (B) Pearson's correlation of the phosphorylation proteomes from two sample groups (three biological replicates for each group). (C) Basic statistical data of MS results. (D) Mass error distribution of all identified phosphorylated peptides. X-axis: Peptide Score; Y-axis: Peptides mass delta. (E) Length distribution of all identified phosphorylated peptides. X-axis: No. of Peptide; Y-axis: Peptide length. 

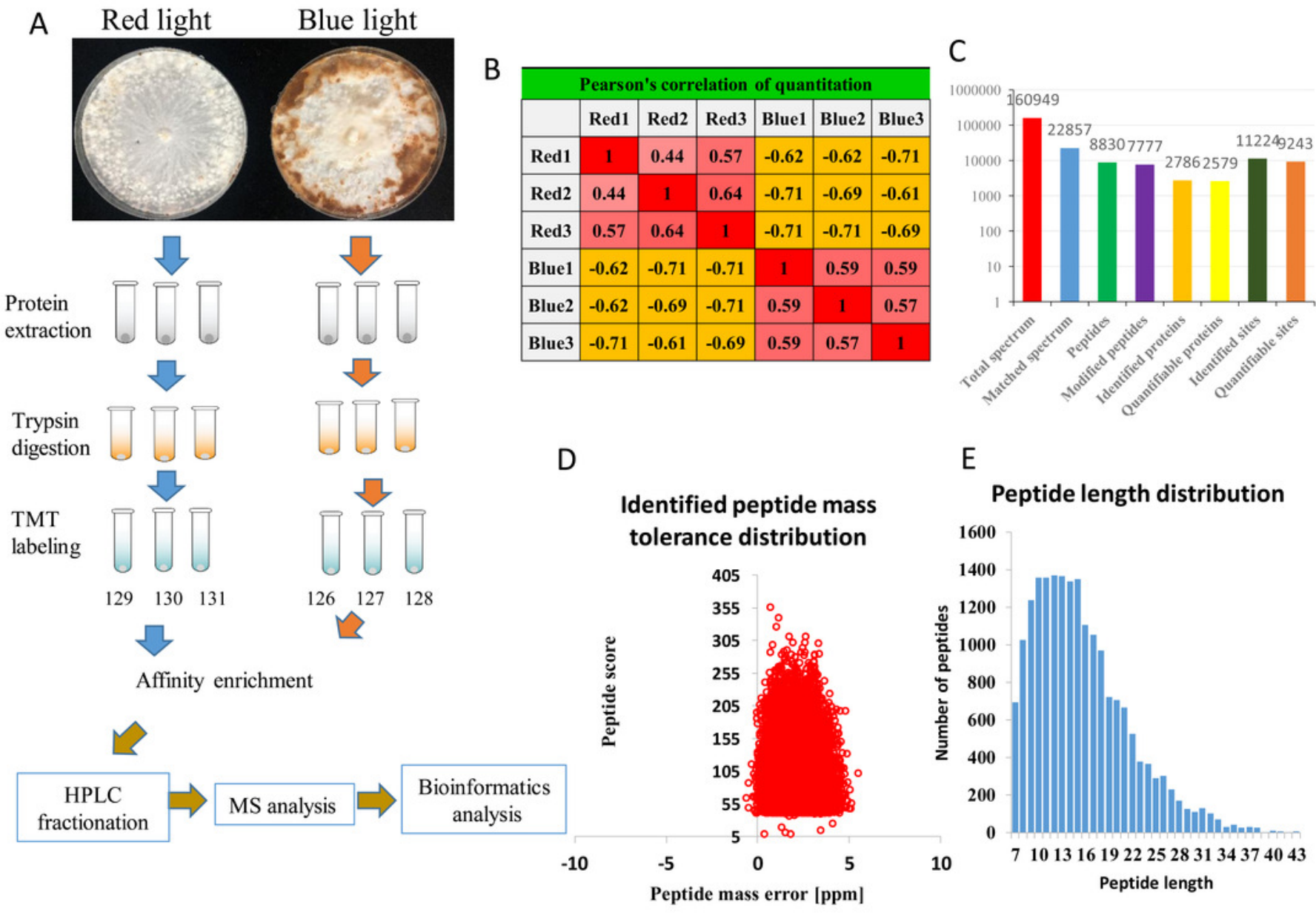
Figure 2

Figure 2 Analysis of the density of phosphorylation sites.

(A) Modification phosphorylated sites distribution of all identified peptides. (B) Comparison of the average densities of phosphorylation sites per protein among various species.
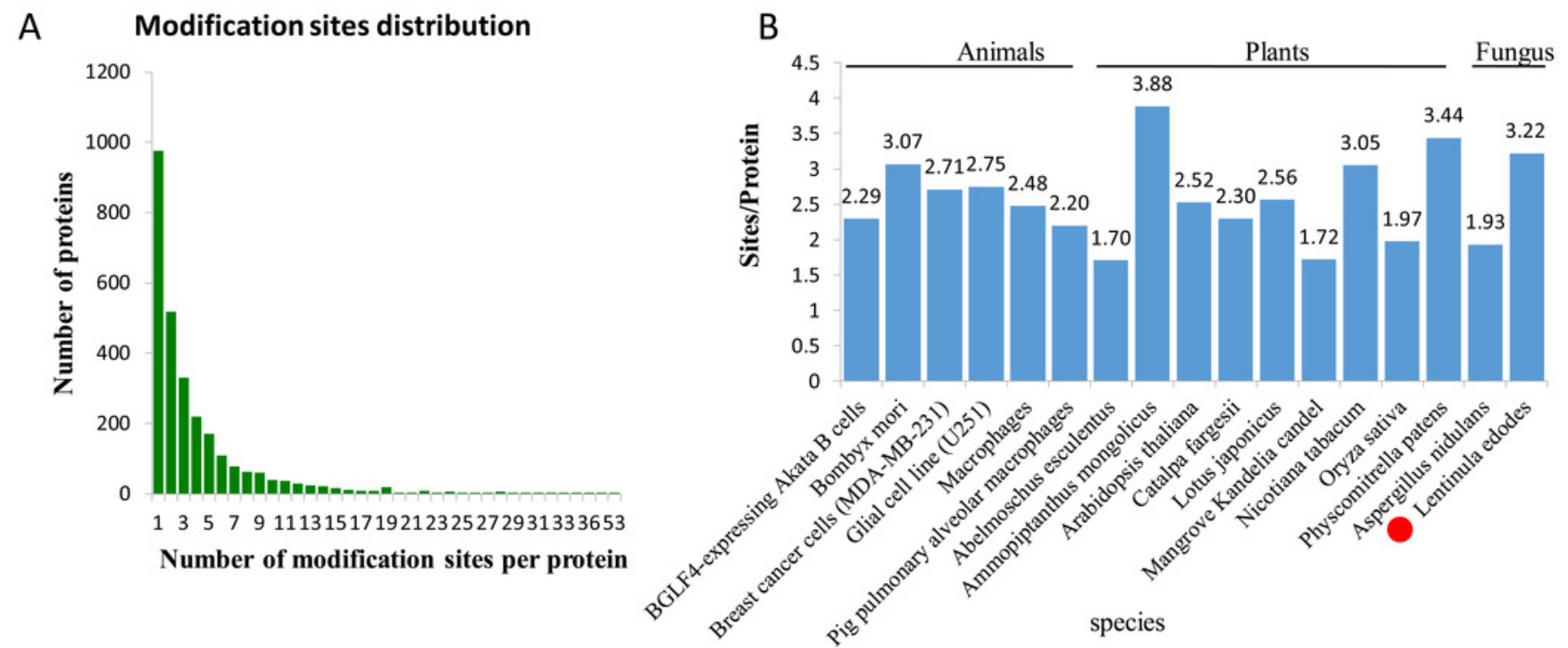
Figure 3

Figure 3 Annotation and classification of all identified phosphorylated proteins.

(A) GO analysis of all phosphorylated proteins. All proteins were classified by GO terms based on their biological process, cellular component and molecular function. (B) The euKaryotic Ortholog Groups annotation clustered all the phosphoproteins into four major categories: Information storage and processing, Cellular processes and signaling, Metabolism and Poorly characterized.(C) Subcellular locations ofall identified phosphorylated proteins.
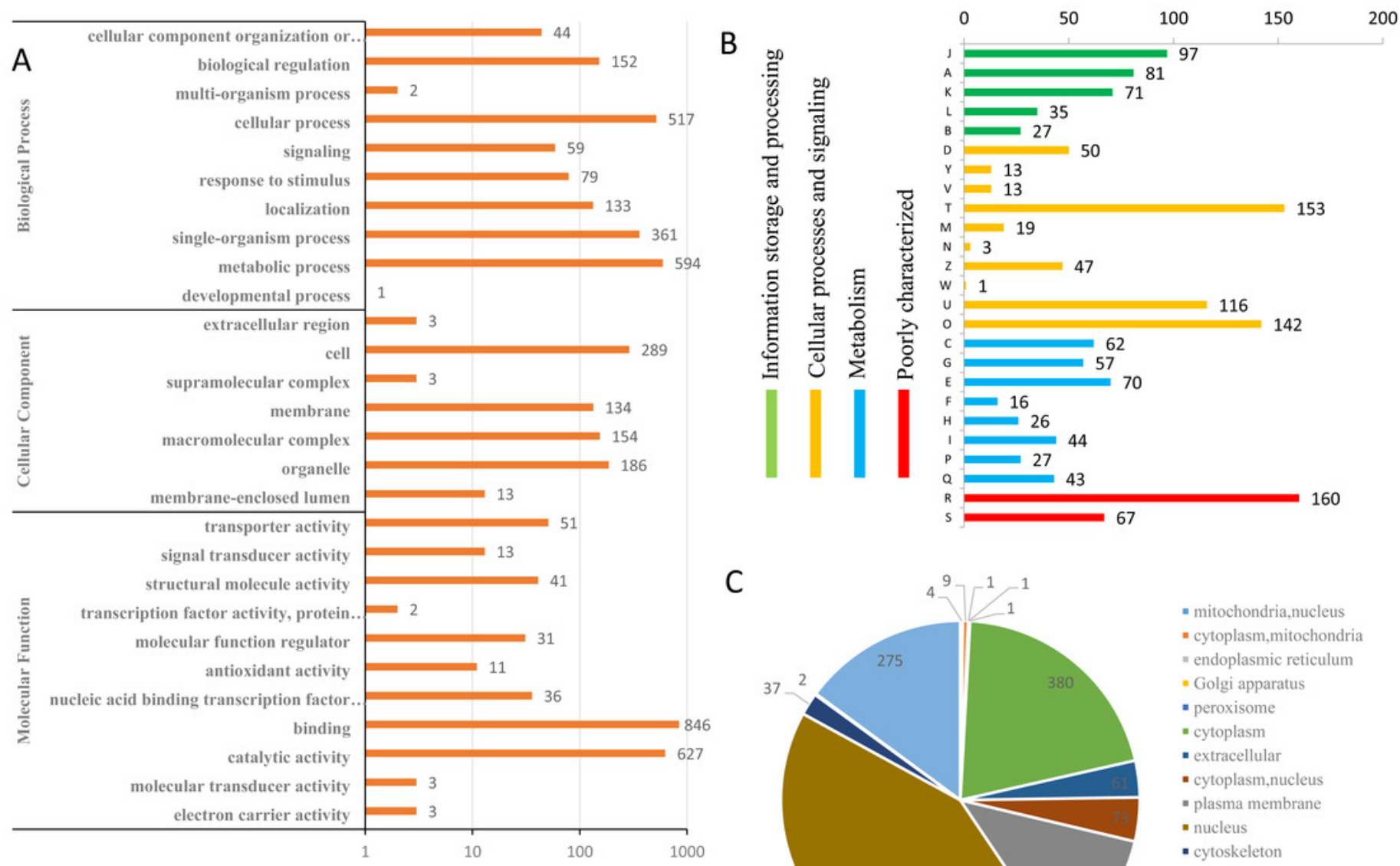

C

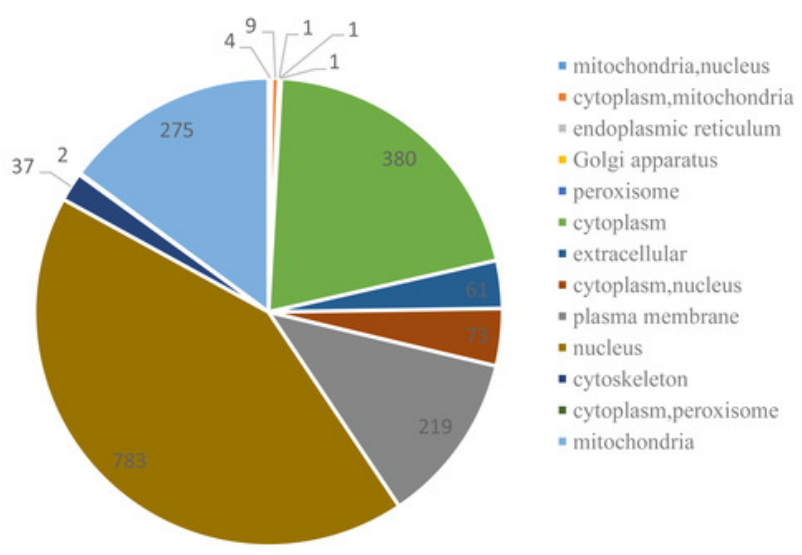




\section{Figure 4}

Figure 4 Phosphosite types and peptide motifs associated with phosphorylation.

(A) The distribution of phosphosites between serine, threonine and tyrosine residues. (B) Motif analysis of the amino acids surrounding the phosphosites. Sequence logo representation of $5 \mathrm{~S}$-based and $5 \mathrm{~T}$-based conserved phosphorylation motifs. (C) A plot showing the relative abundance of amino acids flanking a phosphorylated serine (S) and threonine (T) using the intensity map. Red indicated that this amino acid was significantly enriched near the modification site, and green indicated that this amino acid was significantly reduced near the modification site. Letters represent abbreviations for amino acids 
A

B

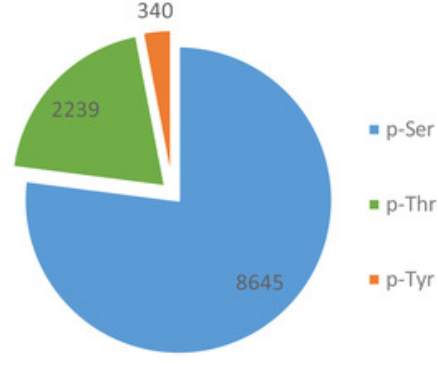

10.

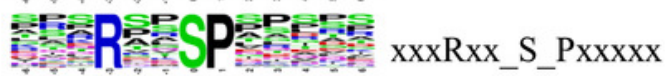

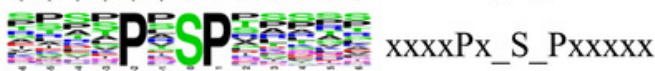

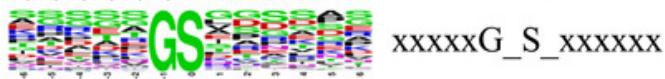

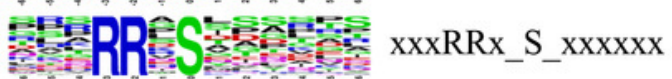

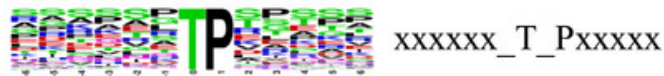

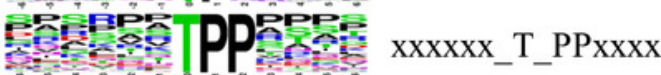

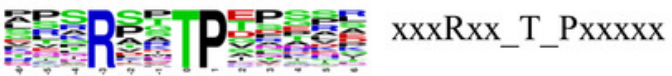

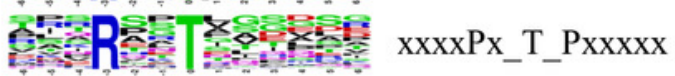

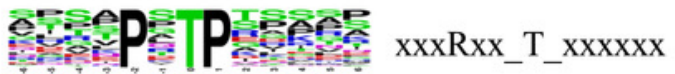

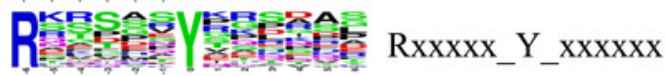

\section{C}

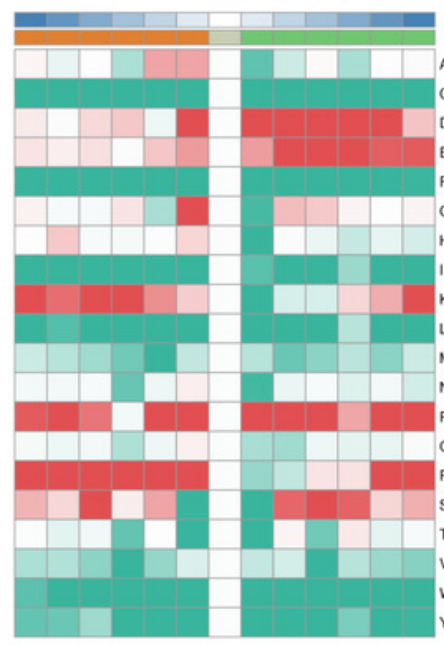

${ }^{10}$ Distance

5

Position

Upstream

Downstream
Modification site 


\section{Figure 5}

Figure 5 Impacts of illumination treatment on phosphorylation proteome levels in fungal mycelia.

(A) Heat map for the accumulation levels of all the identified phosphorylated proteins. Red indicates up-regulation and green indicates down-regulation. The heatmap scale ranges from 0 to +2 . (C).(B) The numbers of up- and down-regulated sites and proteins in red and blue light treatment comparison.(C) Subcellular locations of differentially phosphorylated proteins

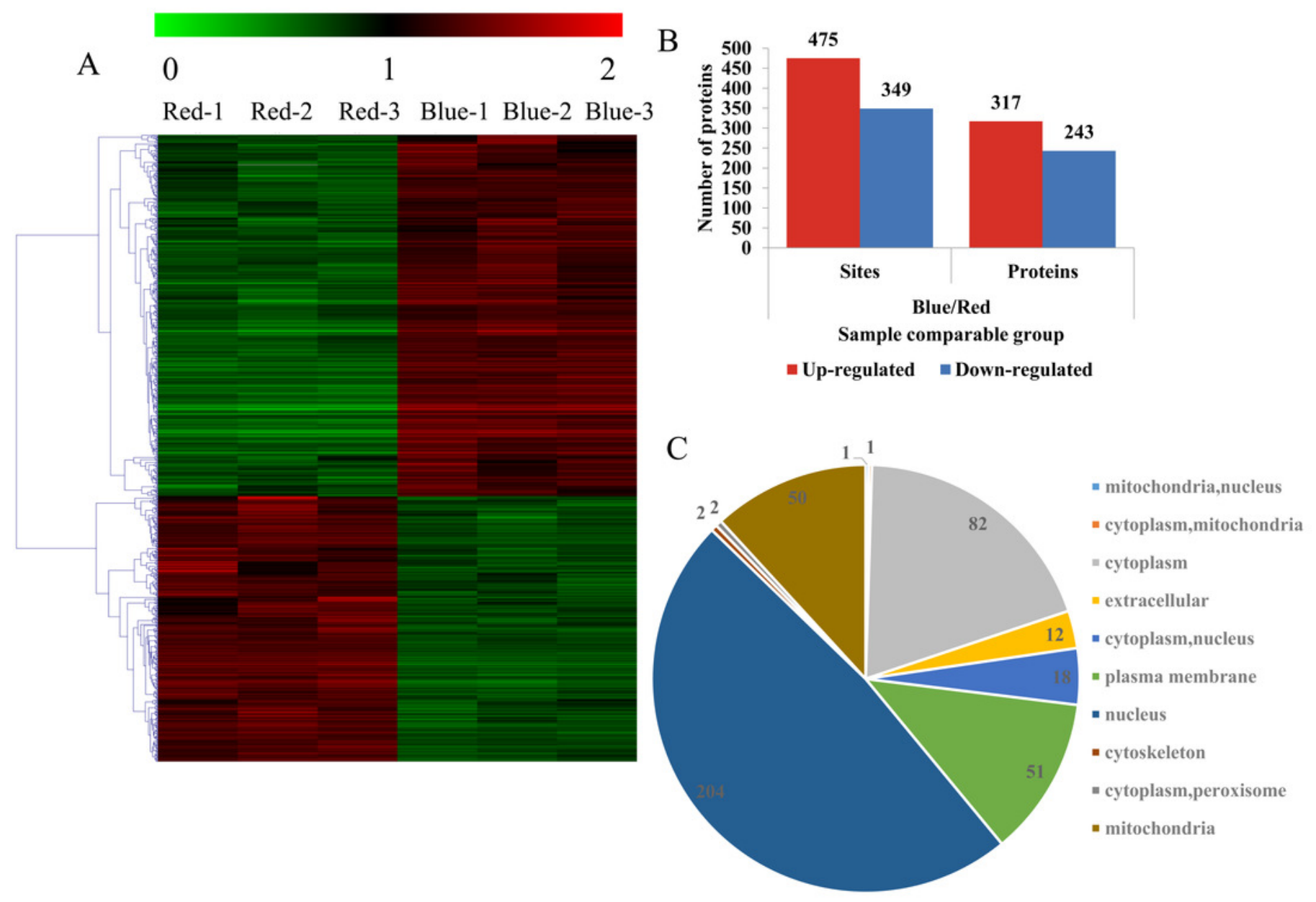


Figure 6

Figure $6 \mathrm{GO}$ enrichment analysis of DPPs based on biological process (A), cellular component (B) and molecular function (C).
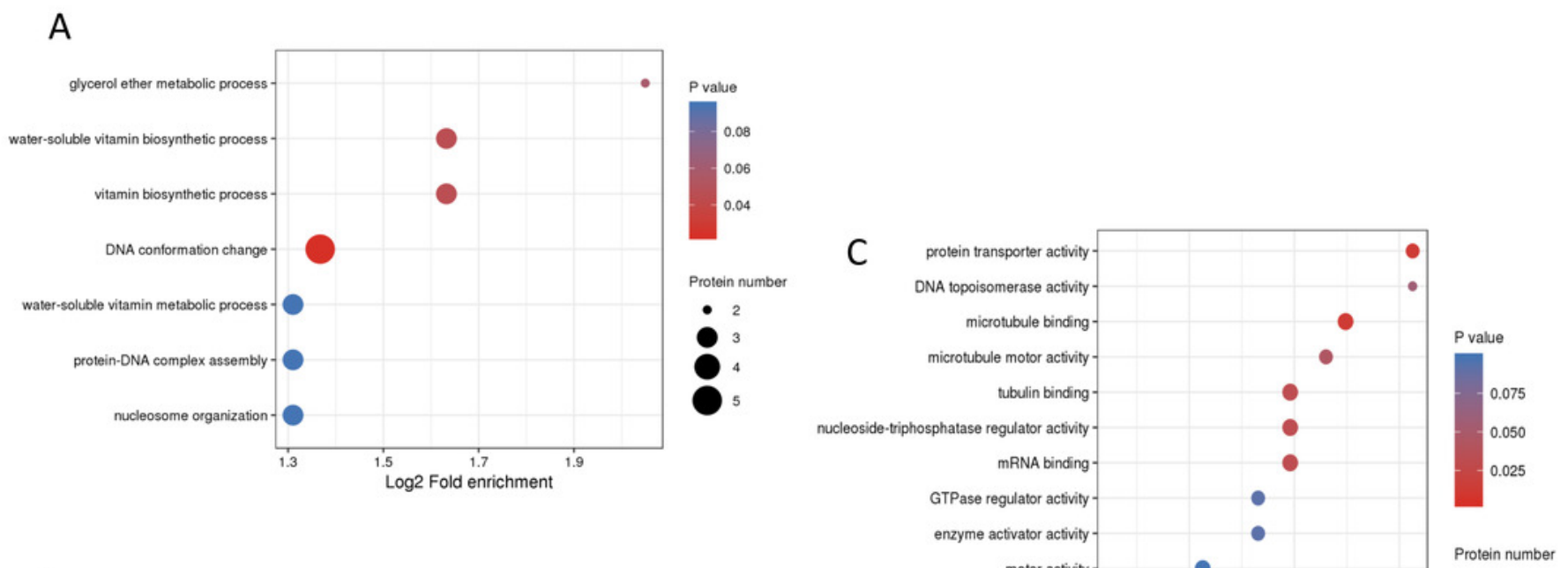

B
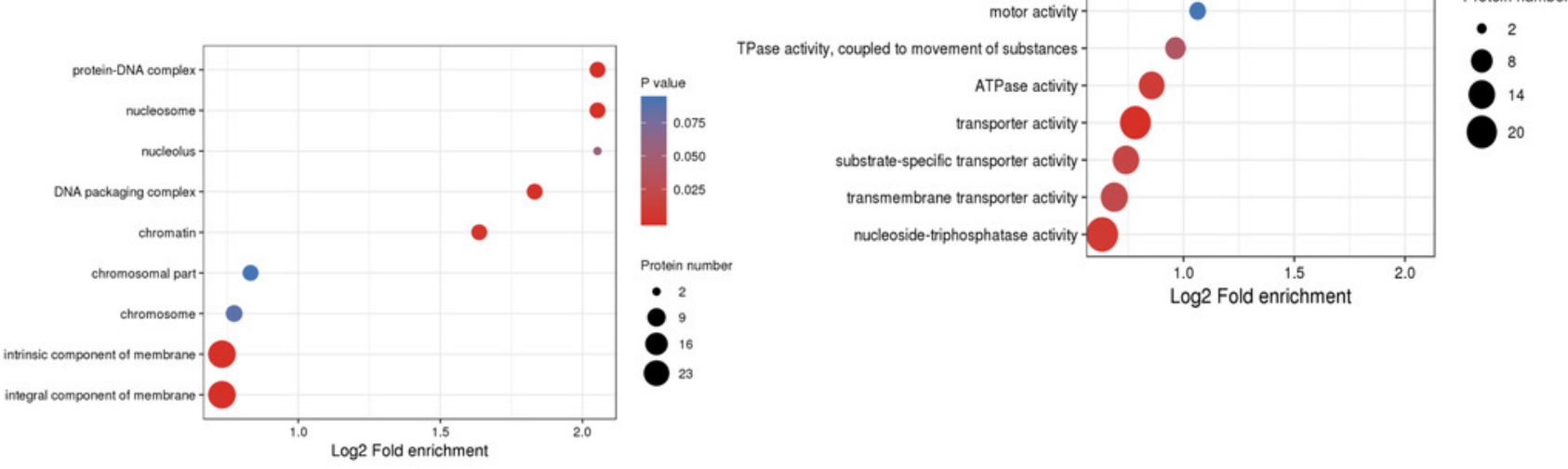


\section{Figure 7}

Figure 7 KEGG and domain enrichment analysis of the DPPs in fungal mycelium between two different illumination treatments.

KEGG enrichment analysis of up- (A) and down-regulated (B) phosphorylated proteins. Protein domains enrichment analysis of up- (C) and down-regulated (D) phosphorylated proteins.

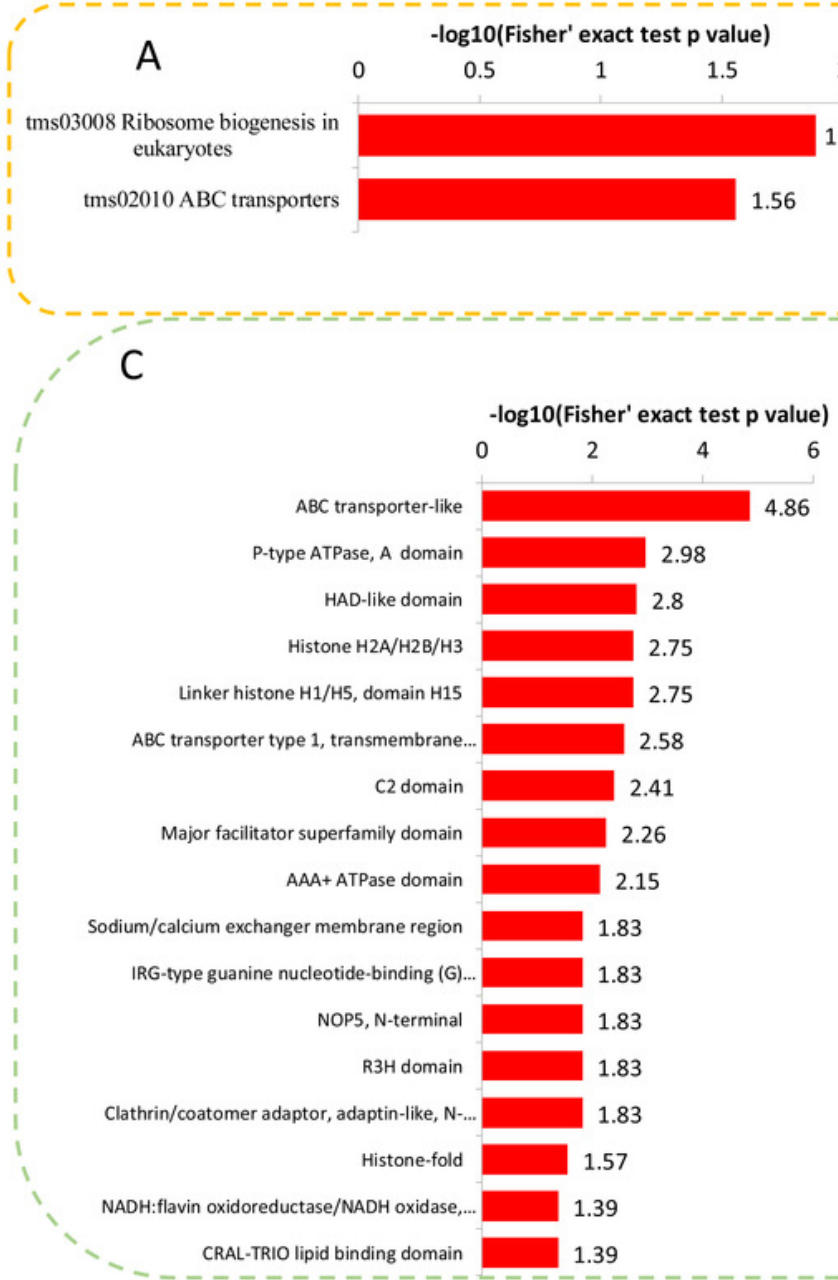

up-regulated proteins
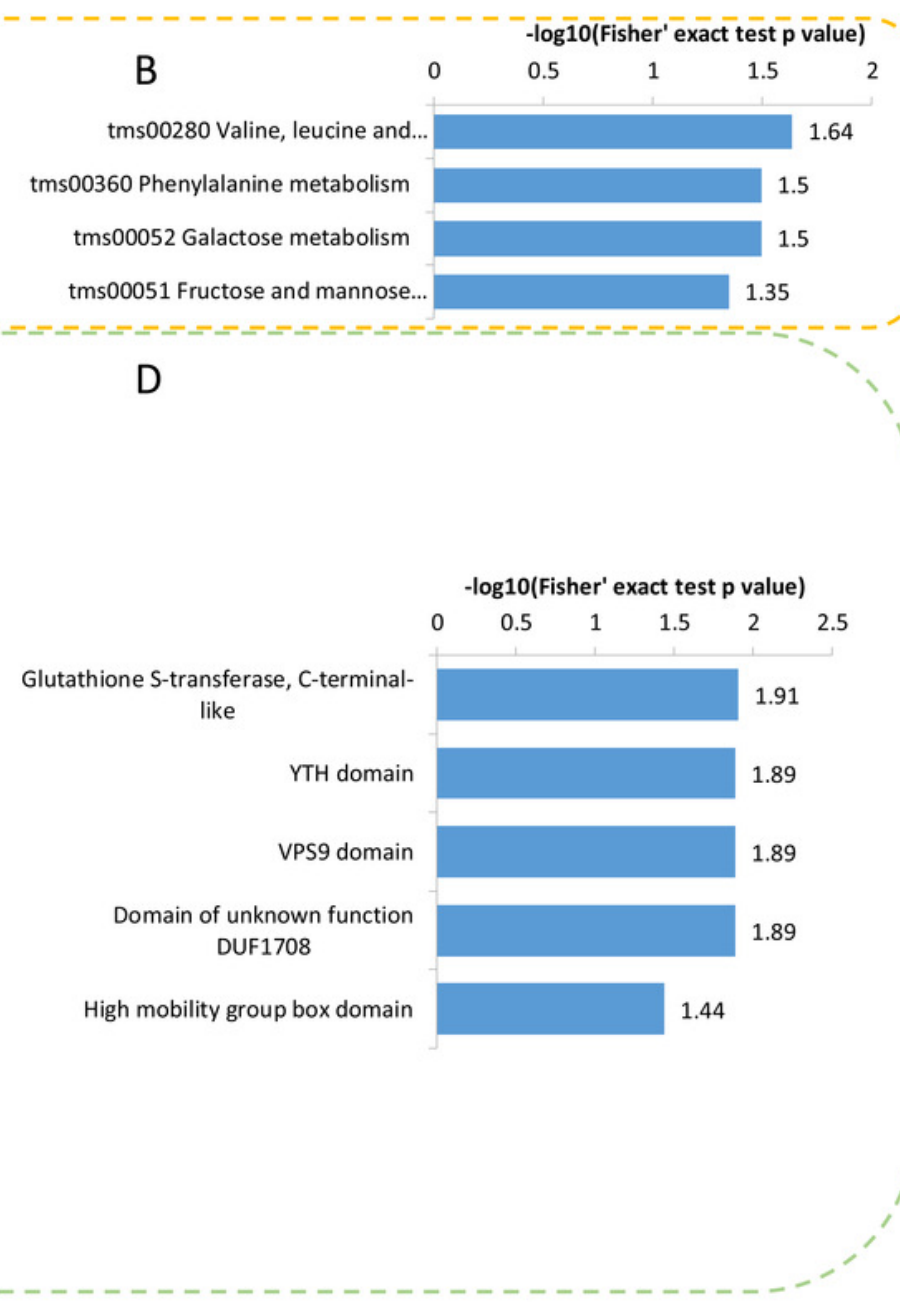

$\mathrm{D}$

down-regulated proteins 
Table $\mathbf{1}$ (on next page)

Table1.List of differentially expressed signal transduction mechanisms related phosphosites 
1 Table1.List of differentially expressed signal transduction mechanisms related phosphosites

\begin{tabular}{|c|c|c|c|c|}
\hline \multirow{2}{*}{$\begin{array}{l}\text { Protein } \\
\text { accession }\end{array}$} & \multirow[b]{2}{*}{ Position Ratio } & \multicolumn{2}{|c|}{ Regulated } & Amino \\
\hline & & Ratio Type & $P$ value & Protein description \\
\hline A0A1Q3DXT2 & 147 & $2.041 \mathrm{Up}$ & $0.000701 \mathrm{~S}$ & $\begin{array}{l}\text { Actin cytoskeleton-regulatory complex } \\
\text { protein pan } 1\end{array}$ \\
\hline A0A1Q3DXT2 & 940 & 0.661 Down & $0.0212 \mathrm{~S}$ & $\begin{array}{l}\text { Actin cytoskeleton-regulatory complex } \\
\text { protein pan } 1\end{array}$ \\
\hline A0A1Q3DXT2 & 340 & $1.566 \mathrm{Up}$ & $0.00104 \mathrm{~S}$ & $\begin{array}{l}\text { Actin cytoskeleton-regulatory complex } \\
\text { protein pan } 1\end{array}$ \\
\hline A0A1Q3DXT2 & 538 & $1.503 \mathrm{Up}$ & $0.000622 \mathrm{~S}$ & $\begin{array}{l}\text { Actin cytoskeleton-regulatory complex } \\
\text { protein pan } 1\end{array}$ \\
\hline A0A1Q3DXT2 & 145 & $2.041 \mathrm{Up}$ & $0.000701 \mathrm{~S}$ & $\begin{array}{l}\text { Actin cytoskeleton-regulatory complex } \\
\text { protein pan } 1\end{array}$ \\
\hline A0A1Q3DXT2 & 626 & $1.573 \mathrm{Up}$ & $0.00602 \mathrm{~S}$ & $\begin{array}{l}\text { Actin cytoskeleton-regulatory complex } \\
\text { protein pan } 1\end{array}$ \\
\hline A0A1Q3EQA0 & 342 & 0.666 Down & $0.0269 \mathrm{~S}$ & Arf gtpase activator \\
\hline A0A1Q3EH65 & 144 & 0.457 Down & $0.00398 \mathrm{~S}$ & $\begin{array}{l}\text { Carbohydrate-binding module family } 21 \\
\text { protein }\end{array}$ \\
\hline A0A1Q3EH65 & 184 & 0.46 Down & $0.000337 \mathrm{~S}$ & $\begin{array}{l}\text { Carbohydrate-binding module family } 21 \\
\text { protein }\end{array}$ \\
\hline A0A1Q3EH65 & 1114 & 0.634 Down & $0.00106 \mathrm{~S}$ & $\begin{array}{l}\text { Carbohydrate-binding module family } 21 \\
\text { protein }\end{array}$ \\
\hline A0A1Q3EH65 & 391 & 0.512 Down & $0.0000778 \mathrm{~S}$ & $\begin{array}{l}\text { Carbohydrate-binding module family } 21 \\
\text { protein }\end{array}$ \\
\hline A0A1Q3EIZ3 & 287 & 0.542 Down & $0.0000823 \mathrm{~S}$ & Casein kinase II subunit beta \\
\hline A0A1Q3EIZ3 & 363 & 0.472 Down & $0.000779 \mathrm{~S}$ & Casein kinase II subunit beta \\
\hline A0A1Q3EHC7 & 350 & $1.787 \mathrm{Up}$ & $0.0024 \mathrm{~S}$ & Ck1 ck1 ck1-d protein kinase \\
\hline A0A1Q3EML6 & 60 & 0.596 Down & $0.00757 \mathrm{~S}$ & Gtpase-activating protein gyp 7 \\
\hline
\end{tabular}




\begin{tabular}{|c|c|c|c|c|}
\hline A0A1Q3DYV9 & 5 & $1.542 \mathrm{Up}$ & $0.00764 \mathrm{~S}$ & Guanine nucleotide-binding protein \\
\hline A0A1Q3DYV9 & 220 & $1.778 \mathrm{Up}$ & $0.000163 \mathrm{~S}$ & Guanine nucleotide-binding protein \\
\hline A0A1Q3EBC7 & 120 & 0.663 Down & $0.00414 \mathrm{~T}$ & HCP-like protein \\
\hline A0A1Q3EQ51 & 108 & $2.293 \mathrm{Up}$ & $0.0123 \mathrm{~S}$ & Kinase-like protein \\
\hline A0A1Q3EEF5 & 191 & 0.653 Down & $8.16 \mathrm{E}-07 \mathrm{Y}$ & Map kinase \\
\hline A0A1Q3EEF5 & 189 & 0.641 Down & $1.16 \mathrm{E}-06 \mathrm{~T}$ & Map kinase \\
\hline A0A1Q3EEF5 & 194 & 0.572 Down & $0.0000373 \mathrm{~T}$ & Map kinase \\
\hline A0A1Q3E4D7 & 4 & 0.566 Down & $0.000739 \mathrm{Y}$ & $\begin{array}{l}\text { Mitogen activated protein kinase-like } \\
\text { protein }\end{array}$ \\
\hline & & & & mRNA stability protein $\mathrm{OS}=$ Lentinula \\
\hline A0A1Q3EII7 & 44 & 0.59Down & $0.00196 \mathrm{Y}$ & edodes \\
\hline A0A1Q3E829 & 28 & 0.651 Down & $0.000319 \mathrm{Y}$ & Neutral alkaline nonlysosomal ceramidase \\
\hline & & & & Non-specific serine/threonine protein \\
\hline A0A1Q3EKW8 & 21 & $1.828 \mathrm{Up}$ & $0.00182 \mathrm{~S}$ & kinase \\
\hline & & & & Non-specific serine/threonine protein \\
\hline A0A1Q3EKW8 & 19 & $1.717 \mathrm{Up}$ & $0.0000797 \mathrm{~S}$ & kinase \\
\hline & & & & Non-specific serine/threonine protein \\
\hline A0A1Q3E982 & 790 & 0.53 Down & $0.023 \mathrm{~S}$ & kinase \\
\hline A0A1Q3E1S4 & 101 & 0.642 Down & $0.00332 \mathrm{~S}$ & Otu-like cysteine \\
\hline A0A1Q3E102 & 696 & $1.667 \mathrm{Up}$ & $0.0108 \mathrm{~S}$ & Phosphatidylinositol 3-kinase VPS34 \\
\hline A0A1Q3E326 & 400 & 0.496 Down & $0.000677 \mathrm{~S}$ & Protein phosphatase $2 \mathrm{c}$ \\
\hline A0A1Q3E326 & 588 & 0.554 Down & $0.0000166 \mathrm{~S}$ & Protein phosphatase $2 \mathrm{c}$ \\
\hline A0A1Q3E326 & 402 & 0.5 Down & $0.0000243 \mathrm{~T}$ & Protein phosphatase $2 \mathrm{c}$ \\
\hline A0A1Q3E326 & 586 & 0.51 Down & $0.0000438 \mathrm{~S}$ & Protein phosphatase $2 \mathrm{c}$ \\
\hline A0A1Q3E326 & 393 & 0.655 Down & $0.00102 \mathrm{~S}$ & Protein phosphatase $2 \mathrm{c}$ \\
\hline A0A1Q3EFR0 & 271 & 0.543 Down & $0.000024 \mathrm{~S}$ & Protein serine threonine phosphatase $2 \mathrm{C}$ \\
\hline
\end{tabular}




\begin{tabular}{|c|c|c|c|c|}
\hline A0A1Q3E8Y4 & 138 & $1.593 \mathrm{Up}$ & $0.000198 \mathrm{~S}$ & Ras guanyl-nucleotide exchange factor \\
\hline A0A1Q3EIH9 & 765 & 0.636 Down & $0.000277 \mathrm{~S}$ & Rho gtpase activator \\
\hline A0A1Q3DW25 & 452 & 0.335 Down & $0.000459 \mathrm{~S}$ & Serine threonine-protein kinase \\
\hline A0A1Q3E8M7 & 137 & 0.648 Down & $0.00158 \mathrm{~S}$ & SGS-domain-containing protein \\
\hline A0A1Q3EKV3 & 265 & $1.703 \mathrm{Up}$ & $0.039 \mathrm{~S}$ & Signal transducer \\
\hline A0A1Q3EKV3 & 267 & $2.602 \mathrm{Up}$ & $0.000018 \mathrm{Y}$ & Signal transducer \\
\hline A0A1Q3EKV3 & 263 & $2.391 \mathrm{Up}$ & 9.39E-07S & Signal transducer $\mathrm{OS}=$ Lentinula edodes \\
\hline A0A1Q3E1B1 & 1413 & $1.776 \mathrm{Up}$ & $0.0000573 \mathrm{~S}$ & Sin component scaffold protein cdc11 \\
\hline A0A1Q3DX25 & 818 & 0.602 Down & $0.0273 \mathrm{~S}$ & TKL TKL-ccin protein kinase \\
\hline A0A1Q3EHP8 & 698 & $2.269 \mathrm{Up}$ & $0.000503 \mathrm{~S}$ & Uncharacterized protein \\
\hline A0A1Q3ECY7 & 1099 & $1.628 \mathrm{Up}$ & $0.000258 \mathrm{~S}$ & Uncharacterized protein \\
\hline A0A1Q3EHP8 & 695 & $2.269 \mathrm{Up}$ & $0.000503 \mathrm{~S}$ & Uncharacterized protein \\
\hline A0A1Q3E1M6 & 515 & 0.586 Down & $0.00232 \mathrm{~S}$ & YTH domain-containing protein 1 \\
\hline A0A1Q3E1M6 & 531 & 0.639Down & $0.0227 \mathrm{~S}$ & YTH domain-containing protein 1 \\
\hline
\end{tabular}


Table 2 (on next page)

Table2. List of differentially expressed carbohydrateactive enzymes family phosphosites 


\begin{tabular}{|c|c|c|c|c|c|c|}
\hline Protein accession & Position & Ratio & $\begin{array}{c}\text { Regulated } \\
\text { Type }\end{array}$ & P value & $\begin{array}{l}\text { Amino } \\
\text { acid }\end{array}$ & Protein description \\
\hline \multicolumn{7}{|l|}{ glycoside hydrolase } \\
\hline A0A1Q3DVW4 & 888 & 1.522 & Up & 0.00618 & S & Glycoside hydrolase family 105 protein \\
\hline A0A1Q3DVY0 & 489 & 1.774 & Up & 0.000241 & S & Glycoside hydrolase family 1 protein \\
\hline A0A1Q3DVY0 & 481 & 1.508 & Up & 0.0398 & S & Glycoside hydrolase family 1 protein \\
\hline A0A1Q3EE19 & 429 & 1.931 & Up & 0.0000401 & S & Glycoside hydrolase family 61 protein \\
\hline \multicolumn{7}{|c|}{$\begin{array}{c}\text { carbohydrate-binding } \\
\text { module }\end{array}$} \\
\hline A0A1Q3DXJ6 & 394 & 0.555 & Down & 0.0000212 & $\mathrm{~T}$ & Carbohydrate-binding module family 48 \\
\hline A0A1Q3DXJ6 & 396 & 0.556 & Down & 0.000962 & $\mathrm{~T}$ & Carbohydrate-binding module family 48 \\
\hline A0A1Q3DXJ6 & 377 & 0.483 & Down & 0.00000158 & S & Carbohydrate-binding module family 48 \\
\hline A0A1Q3DXJ6 & 409 & 0.503 & Down & 0.0000161 & S & Carbohydrate-binding module family 48 \\
\hline A0A1Q3DXJ6 & 380 & 0.508 & Down & 0.0000025 & $S$ & Carbohydrate-binding module family 48 \\
\hline A0A1Q3DXJ6 & 388 & 0.451 & Down & 0.0000568 & $S$ & Carbohydrate-binding module family 48 \\
\hline A0A1Q3E7W8 & 134 & 0.561 & Down & 0.0000969 & S & Carbohydrate-binding module family 12 \\
\hline A0A1Q3EH65 & 1114 & 0.634 & Down & 0.00106 & S & Carbohydrate-binding module family 21 \\
\hline A0A1Q3EH65 & 391 & 0.512 & Down & 0.0000778 & S & Carbohydrate-binding module family 21 \\
\hline A0A1Q3EH65 & 184 & 0.46 & Down & 0.000337 & S & Carbohydrate-binding module family 21 \\
\hline A0A1Q3EH65 & 144 & 0.457 & Down & 0.00398 & S & Carbohydrate-binding module family 21 \\
\hline
\end{tabular}

carbohydrate esterase

$\begin{array}{ccccccc}\text { A0A1Q3E195 } & 171 & 0.312 & \text { Down } & 0.000639 & \mathrm{~S} & \begin{array}{c}\text { Lipase from carbohydrate esterase family } \\ \text { ce10 }\end{array} \\ \text { A0A1Q3EGY1 } & 39 & 0.605 & \text { Down } & 0.000116 & \mathrm{~T} & \begin{array}{c}\text { Lipase from carbohydrate esterase family } \\ \text { ce10 }\end{array}\end{array}$




$\begin{array}{cccccccc}\text { glycosyl transferase } & & & & & & \\ \text { A0A1Q3DXW9 } & 1240 & 1.663 & \mathrm{Up} & 0.000342 & \mathrm{~S} & \text { Glycosyltransferase family } 20 \text { protein } \\ \text { A0A1Q3E591 } & 146 & 0.655 & \text { Down } & 0.00272 & \mathrm{~T} & \text { Glycosyltransferase family } 4 \text { protein } \\ \text { A0A1Q3E591 } & 24 & 2.532 & \mathrm{Up} & 0.0291 & \mathrm{~S} & \text { Glycosyltransferase family } 4 \text { protein } \\ \text { A0A1Q3EH60 } & 1581 & 1.585 & \mathrm{Up} & 0.000836 & \mathrm{~S} & \text { Glycosyltransferase family } 2 \text { protein } \\ \text { A0A1Q3EI36 } & 235 & 0.64 & \text { Down } & 0.009 & \mathrm{~S} & \text { Glycosyltransferase Family 22 protein } \\ \text { A0A1Q3ERC2 } & 75 & 0.622 & \text { Down } & 0.00812 & \mathrm{~T} & \text { Glycosyltransferase family } 2 \text { protein }\end{array}$

1 Table2. List of differentially expressed carbohydrateactive enzymes family phosphosites 